\title{
Association between subjective actual sleep duration, subjective sleep need, age, body mass index, and gender in a large sample of young adults
}

This article was published in the following Dove Press journal:

Neuropsychiatric Disease and Treatment

9 January 2015

Number of times this article has been viewed

Nadeem Kalak'

Serge Brand ${ }^{1,2}$

Johannes Beck'

Edith Holsboer-Trachsler'

MAxel Wollmer ${ }^{1,3}$

'Psychiatric Clinics of the University of Basel, ${ }^{2}$ Department of Sport and Health Science, Division of Sport Science, University of Basel, Basel, Switzerland; ${ }^{3}$ Asklepios Clinic North Ochsenzoll, Asklepios Campus Hamburg, Medical Faculty, Semmelweis University, Hamburg, Germany
Correspondence: Nadeem Kalak Psychiatric Clinics of the University of Basel, Center for Affective, Stress and Sleep Disorder, Wilhelm Klein-Strasse 27, CH-40I2 Basel, Switzerland

Tel +4I 6I 3255236

Fax +4I 6I32555I3

Email nadeem.kalak@upkbs.ch
Background: Poor sleep is a major health concern, and there is evidence that young adults are at increased risk of suffering from poor sleep. There is also evidence that sleep duration can vary as a function of gender and body mass index (BMI). We sought to replicate these findings in a large sample of young adults, and also tested the hypothesis that a smaller gap between subjective sleep duration and subjective sleep need is associated with a greater feeling of being restored.

Methods: A total of 2,929 university students (mean age $23.24 \pm 3.13$ years, $69.1 \%$ female) took part in an Internet-based survey. They answered questions related to demographics and subjective sleep patterns.

Results: We found no gender differences in subjective sleep duration, subjective sleep need, BMI, age, or feeling of being restored. Nonlinear associations were observed between subjective sleep duration, BMI, and feeling of being restored. Moreover, a larger discrepancy between subjective actual sleep duration and subjective sleep need was associated with a lower feeling of being restored.

Conclusion: The present pattern of results from a large sample of young adults suggests that males and females do not differ with respect to subjective sleep duration, BMI, or feeling of being restored. Moreover, nonlinear correlations seemed to provide a more accurate reflection of the relationship between subjective sleep and demographic variables.

Keywords: young adults, subjective sleep duration, subjective sleep need, body mass index, Internet-based study

\section{Introduction}

Restorative sleep is essential for higher cognitive, ${ }^{1-5}$ emotional, ${ }^{6-11}$ and social and behavioral performance. ${ }^{12-17}$ Sleep duration decreases over the life span, with a marked reduction in overnight sleep from childhood to adulthood. ${ }^{18}$ There is also evidence that sleep quantity ${ }^{3,19-22}$ and sleep quality change as a function of lifestyle factors, such as leisure activities, vocational constraints (such as overtime and shift work), academic achievement (including periods of increased stress due to final examinations), and social activities (such as sports, concerts, and meeting friends). ${ }^{12,13,23,24}$ More specifically, findings have shown that university students may experience increased stress and report more sleep complaints. In this regard, for example, Lund et $\mathrm{al}^{25}$ showed that over $60 \%$ of people aged 17-24 years suffer from sleep difficulties, along with a broad range of both physical and psychologic issues. ${ }^{26,27}$

Previous research in Western countries has shown that nearly $40 \%$ of young adults (aged 18-25 years) are overweight or obese, ${ }^{28}$ and that obesity emerging during childhood persists, such that overweight children are at greater risk for weight gain 
and for retaining this weight into adulthood. ${ }^{29-33}$ Further, previous studies ${ }^{34,35}$ have shown an association between shorter sleep duration and higher body mass index (BMI) in adolescents and young adults (aged 14-27 years). In particular, Hart et $\mathrm{al}^{36}$ reported a U-shaped function, with sleep duration that was either too short (less than 6 hours per night) or too long (more than 9 hours per night) being associated with higher BMI (weight in $\mathrm{kg} /$ height in $\mathrm{m}^{2}$ ) during late adolescence and early adulthood. These findings replicate previous research indicating a link between sleep duration and obesity. ${ }^{36,37}$

Moreover, epidemiologic and experimental studies have consistently reported that, compared with males, females complain more about poor sleep. ${ }^{38}$ The underlying mechanisms remain unclear, ${ }^{39}$ and there is a suggestion that poor sleep as reported by females might be associated with further psychologic issues, such as depression and anxiety symptoms, ${ }^{40}$ rumination, and emotion-focused coping strategies. ${ }^{41}$

Further, a wealth of studies has shown that young adults generally do not sleep as long as they should. To illustrate: whereas Maslowsky and Ozer ${ }^{42}$ observed that 22-year-olds slept about 8.5 hours per night, across early adulthood to 32 years, sleep duration decreased gradually to 7.7 hours per night. Normative data also suggest that sleep duration should be 8.5 hours a night in young adults in order for them to perform well cognitively, emotionally, behaviorally, and socially during the day. ${ }^{25,43}$

Moreover, data from experimental studies have repeatedly confirmed a dose-response relationship between shorter sleep duration and cognitive ${ }^{44}$ and emotional ${ }^{8,45,46}$ performance. Accordingly, we believe that a greater gap between actual sleep duration and sleep need might be associated with reduced feelings of being restored. Indeed, Lemola et $\mathrm{al}^{47}$ showed that a greater difference between current and needed sleep duration was associated with poorer sleep quality and decreased subjective well-being. ${ }^{47}$ Likewise, Kalak et al ${ }^{11}$ showed that sleep duration was associated with subjective psychological well-being both cross-sectionally and longitudinally.

To summarize, there is reason to believe that sleep duration can be insufficient in early adulthood and that sleep duration may vary as a function of gender and BMI. Surprisingly, to the best of our knowledge, so far no study has addressed these issues concomitantly. ${ }^{48,49}$ The aim of the present study was therefore to shed more light on the relationship between actual sleep duration and sleep need, BMI, and gender in a large sample of young adults.
Four hypotheses were formulated, as follows. First, following Lemola et $\mathrm{al},{ }^{47}$ we predicted that longer subjective actual sleep duration and a smaller difference between subjective actual sleep duration and subjective sleep need would be associated with a greater feeling of being restored. Second, following Carskadon and $\mathrm{Acebo}^{50}$ and Carskadon et $\mathrm{al}^{51}$ we hypothesized that young adults would report a subjective actual sleep duration that was shorter than their subjective sleep need. Third, following Armitage and Hoffmann, ${ }^{40}$ we anticipated that female participants would report longer subjective actual sleep duration and a lower feeling of being restored than male participants. Finally, following Hart et $\mathrm{al}^{36}$ we expected a U-shaped relationship between BMI and subjective sleep duration.

\section{Materials and methods}

The survey was conducted between the beginning of spring 2009 and the end of summer 2009. Participants were recruited via electronic advertisements posted at several universities in Germany and in the German-speaking part of Switzerland. The entire study was performed as an online survey.

Previous studies comparing Internet-administered questionnaires with paper-and-pencil questionnaires have found the electronic version to have no relative disadvantages. ${ }^{52-54}$ Accordingly, commercially available software (Globalpark, http://www.globalpark.com) was used for data collection. The study was approved by the local ethics committee (Ethikkommission beider Basel, approved, 66/09) and conducted according to the rules laid down in the Declaration of Helsinki.

\section{Participants and procedure}

A total of 2,929 university students (mean age $23.24 \pm 3.13$ years, $69.1 \%$ female) took part in an Internetbased survey. The students answered questions related to demographics and sleep patterns.

Participants completed the online questionnaire within 5-10 minutes. On the first page of the survey screen, potential participants were informed about the purpose of the study, the voluntary basis of their participation, and the anonymized data storage. Additionally, participants were advised that they could stop or withdraw from the study without giving any reason. To avoid repeat participation, the software was designed to block recruitment of individuals whose IP address had already been used. Data were automatically gathered and afterwards converted into an SPSS ${ }^{\circledR}$ file for further analysis. Further, as an incentive to participation, 35 iPods $^{\circledR}$ were raffled. However, for participation in the raffle drawing, participants had to provide an email address. 
To obtain consent, on the first page participants had to tick a box with the following statement:

I do fully understand the aims and scopes of the present study; I know that data are stored on a secure server, that no personal data are required, and that I can withdraw from and stop the study at any time. I also know that I have to indicate an email address, if I want to participate at the raffle drawing.

\section{Online questionnaire}

Participants answered the following items: age (years), gender, subjective actual sleep duration (hours) and subjective sleep need (hours) in the last 2 weeks, height $(\mathrm{cm})$, weight $(\mathrm{kg})$, and feeling of being restored after sleep in the last 2 weeks on a five-point Likert scale, with anchor points of 1 ("not at all restored") to 5 ("completely restored").

\section{Statistical analysis}

To compare demographic and sleep-related variables between male and female participants, a series of $t$-tests was performed. Where variances were not equal, instead of the classical Student's $t$-test, the more robust Welch (W) test was performed. ${ }^{55,56} \mathrm{Next}$, based on previous research showing nonlinear associations between sleep, BMI, ${ }^{36}$ and psychological functioning, ${ }^{57}$ nonlinear correlations were computed between subjective sleep duration, BMI, feeling of being restored, and the difference between subjective actual sleep duration and subjective sleep need. The nominal level of statistical significance was set at an alpha of $P<0.05$. However, we focused on effect sizes according to Cohen. ${ }^{58}$ The reason was that $t$-tests are very sensitive to sample size, ${ }^{59}$ and our data related to a large sample. Therefore, we chose to report not merely statistically significant effects $(P<0.05)$. All statistical computations were performed with Statistical
Package for the Social Sciences version 20 software (IBM Corporation, Armonk, NY, USA) for Windows ${ }^{\circledR}$.

\section{Results}

Table 1 reports the descriptive and inferential statistics. Negligible gender differences were found for subjective actual sleep duration, BMI, feeling of being restored, and the gap between subjective actual sleep duration and subjective sleep need (all Cohen's $d<0.38$ ).

Table 2 reports the associations between subjective actual sleep duration, BMI, feeling of being restored, and the gap between subjective actual sleep duration and subjective sleep need, separated for gender. Negligible gender differences were found (Table 1). Older age was associated with higher BMI, lower subjective sleep need, and a smaller gap between subjective actual sleep duration and subjective sleep need. Longer subjective actual sleep duration was associated with greater subjective sleep need, a feeling of being restored, and a smaller gap between subjective actual sleep duration and subjective sleep need. Greater subjective sleep need was associated with a lower feeling of being restored and a greater gap between subjective actual sleep duration and subjective sleep need. A greater feeling of being restored was associated with a lower gap between subjective actual sleep duration and subjective sleep need.

Table 3 reports a nonlinear association between subjective actual sleep duration and BMI, ie, shorter and longer subjective actual sleep durations were associated with higher BMI. A nonlinear association was also observed between subjective actual sleep duration and the subjective actual versus subjective need gap, ie, longer and shorter subjective actual sleep durations were associated with a greater subjective gap. A nonlinear association between subjective actual sleep duration and feeling of being restored was observed, ie, shorter and longer subjective actual sleep durations were

Table I Descriptive and inferential statistics comparing gender differences with regard to age, BMI, subjective actual sleep duration, subjective sleep need, feeling of being restored, and gap between sleep need and actual sleep duration

\begin{tabular}{|c|c|c|c|c|c|c|c|}
\hline & \multicolumn{2}{|c|}{ Female $(n=2,022)$} & \multicolumn{2}{|c|}{ Male $(n=906)$} & \multicolumn{3}{|l|}{ Differences } \\
\hline & M & SD & $\mathbf{M}$ & SD & Test $(d f)$ & $P$-value & Cohen's d \\
\hline Age, years & 23.14 & 3.08 & 23.46 & 3.22 & $w(2,926)=2.57$ & 0.010 & 0.10 \\
\hline BMI & 21.98 & 3.66 & 23.35 & 3.51 & $t(2,923)=9.51$ & 0.000 & 0.38 \\
\hline SASD & 8.83 & 1.94 & 8.19 & 2.05 & $t(2,926)=8.05$ & 0.000 & 0.32 \\
\hline SSN & 10.73 & 2.06 & 10.41 & 2.30 & $w(2,926)=3.77$ & 0.000 & 0.15 \\
\hline FBR & 3.38 & 0.85 & 3.36 & 0.82 & $t(2,926)=0.54$ & 0.590 & 0.02 \\
\hline SSN-SASD & 1.91 & 2.34 & 2.22 & 2.47 & $t(2,926)=3.28$ & 0.001 & 0.13 \\
\hline
\end{tabular}

Notes: Cohen's $d=0.2-0.49$ little effect; $d=0.5-0.79$ middle effect; $d>0.8$ large effect. Underweight, BMI, $18.5 \mathrm{~kg} / \mathrm{m}^{2}$; overweight, BMI $25.0-29.9 \mathrm{~kg} / \mathrm{m}^{2}$.

Abbreviations: M, mean; SD, standard deviation; BMl, body mass index; SASD, subjective actual sleep duration; SSN, subjective sleep need; FBR, feeling being restored; SSN-SASD, gap between subjective sleep need and subjective actual sleep duration. 
Table 2 Correlations between BMI, subjective actual sleep duration, subjective sleep need, feeling of being restored, and gap between sleep need and actual sleep duration, separated by gender

\begin{tabular}{llllll}
\hline & BMI & SASD & SSN & FBR & SSN-SASD \\
\hline Age (f) & $0.099^{* * *}$ & -0.022 & $-0.150^{* * *}$ & 0.037 & $-0.114^{* * *}$ \\
Age (m) & $0.154^{* *}$ & 0.005 & $-0.234^{* * *}$ & $0.073^{*}$ & $-0.223^{* * *}$ \\
BMI (f) & & -0.042 & 0.014 & -0.021 & $0.047^{*}$ \\
BMI (m) & & $-0.097^{* *}$ & -0.061 & -0.019 & 0.024 \\
SASD (f) & & & $0.313^{* * *}$ & $0.284^{* * *}$ & $-0.551^{* * *}$ \\
SASD (m) & & & $0.361^{* * *}$ & $0.238^{* * *}$ & $-0.493^{* * *}$ \\
SSN (f) & & & & $-0.193^{* * *}$ & $0.620^{* * *}$ \\
SSN (m) & & & & $-0.195^{* * *}$ & $0.633^{* * *}$ \\
FBR (f) & & & & & $-0.403 * * *$ \\
FBR (m) & & & & & $-0.380^{* * *}$ \\
\hline
\end{tabular}

Notes: $\mathrm{n}=2,929, * \mathrm{p}<0.05, * * \mathrm{p}<0.01, * * * \mathrm{p}<0.001$.

Abbreviations: $f$, female; $m$, male; BMI, body mass index; SASD, subjective actual sleep duration; SSN, subjective sleep need; FBR, feeling being restored; SSN-SASD, gap between subjective sleep need and subjective actual sleep duration.

associated with a lower feeling of being restored. A nonlinear relationship was observed between the subjective actual versus subjective need gap and feeling of being restored, ie, negative and positive differences in subjective gap were associated with a lower feeling of being restored.

\section{Discussion}

Contrary to expectations, in a large sample of young adults, we found negligible gender differences with regard to subjective actual sleep duration, BMI, age, feeling of being restored, and the gap between subjective actual and subjective sleep need. Moreover, nonlinear correlations mirrored the associations between subjective actual sleep duration, feeling of being restored, BMI, and the gap between subjective actual sleep duration and subjective sleep need more accurately than linear correlations. Four hypotheses were formulated and each of these is now considered in turn.

With the first hypothesis, we expected that a greater feeling of being restored would be associated with both a longer subjective actual sleep duration and a smaller difference between subjective actual sleep duration and subjective sleep need. Both predictions were confirmed. The present findings are therefore in accordance with others reporting a link between subjective sleep duration and subjective estimation of restoring and sufficient sleep. ${ }^{47}$ However, the present data add to the existing literature in that we were able to confirm this association in a large sample of young adults, and showed that the feeling of restoring sleep was closely associated with the subjective estimate of the match between subjective actual sleep duration and subjectively needed sleep duration. In other words, the more a person estimates that she or he sleeps as long as she or he subjectively needs to sleep, the more that person reports being restored. Put more simply, it seems that the mere estimation of a good match between subjective actual sleep duration and needed sleep duration is sufficient to produce a feeling of having restoring and adequate sleep. ${ }^{60}$

Our second hypothesis ${ }^{50,51}$ was that young adults would report a subjective sleep duration that was shorter than the subjective sleep need. This hypothesis was fully supported. Thus, the present data mirror previous results, ${ }^{25,43,61}$ although again we expand on previous work in that this pattern of results was confirmed with a large sample of young adults. However, we also note that the mean subjective actual sleep duration was about 8.5 hours (with individual and genderrelated differences), and that this subjectively reported sleep duration would match previous findings (Maslowsky and $\mathrm{Ozer}^{42}$ ) and the recommended sleep duration for young

Table 3 Linear and nonlinear regression between subjective actual sleep duration and BMI, subjective actual sleep duration and gap between subjective sleep need and subjective actual sleep duration, subjective actual sleep duration and feeling of being restored, and gap between subjective sleep need and subjective actual sleep duration and feeling of being restored

\begin{tabular}{|c|c|c|c|c|c|c|c|}
\hline & & $R$ & $R^{2}$ & $\Delta$ in $R^{2}$ & $F(d f)$ & $P$-value & Beta \\
\hline \multirow[t]{2}{*}{ SASD and BMI } & Ir & 0.083 & 0.007 & 0.007 & $(12,923)=20.13$ & $<0.0001$ & $-0.339 * *$ \\
\hline & $\mathrm{nlr}$ & 0.098 & 0.010 & 0.003 & $(12,922)=7.87$ & $<0.00$ I & $0.26 I^{* *}$ \\
\hline \multirow[t]{2}{*}{ SASD and SSN-SASD } & Ir & 0.534 & 0.285 & 0.285 & $(12,927)=1,167.29$ & $<0.001$ & $-0.764 * *$ \\
\hline & $\mathrm{nlr}$ & 0.536 & 0.287 & 0.002 & $(12,926)=9.04$ & $<0.01$ & $0.235^{* *}$ \\
\hline \multirow[t]{2}{*}{ SASD and FBR } & Ir & 0.286 & 0.072 & 0.072 & $(12,927)=26.06$ & $<0.001$ & $0.931 * *$ \\
\hline & $\mathrm{nlr}$ & 0.300 & 0.090 & 0.018 & $(12,926)=58.90$ & $<0.000$ I & $-0.677^{* *}$ \\
\hline \multirow[t]{2}{*}{ SSN-SASD and FBR } & Ir & 0.396 & 0.156 & 0.156 & $(I 2,927)=542.84$ & $<0.001$ & $-0.27 * *$ \\
\hline & $\mathrm{nlr}$ & 0.415 & -0.172 & 0.016 & $(12,926)=54.96$ & $<0.0001$ & $-0.177^{* *}$ \\
\hline
\end{tabular}

Notes: Linear regression is an approach for modeling the relationship between a scalar dependent variable and explanatory variables. Nonlinear regression modeled observational data by a function which is a nonlinear combination of the model parameters and depends on independent variables. $* * P<0.01$.

Abbreviations: Ir, linear regression; $n l r$, nonlinear regression; $R$, correlation; $R^{2}, r$ square correlation; BMI, body mass index; SASD, subjective actual sleep duration; FBR, feeling being restored; SSN-SASD, gap between subjective sleep need and subjective actual sleep duration. 
adults. ${ }^{25,43}$ In this regard, it remains unclear as to what extent the present sample is representative of young adults as a whole, and to what extent young adults attending university might have the privilege of sleeping according to a selfpaced schedule.

Third, following Armitage and Hoffmann, ${ }^{40}$ we anticipated that females would report a longer subjective sleep duration and less feeling of being restored than males. However, following $\mathrm{Cohen}^{58}$ and $\mathrm{Zhu},{ }^{59}$ emphasizing not $P$-values but effect sizes, no meaningful gender differences were observed. Therefore, the present data are at odds with numerous studies showing that young adult females sleep less and need more sleep, and report more sleep complaints than males. Unfortunately, the data do not allow a deeper insight into the underlying mechanisms. Although highly speculative, the lack of a gender difference might be explained by the population sampled. First, only adults aged 18-30 years were recruited and were exclusively from a university student population. Second, given that university students are more reliant on self-paced timetables, this might have obscured the presence of sleep complaints arising from the constraints of externally determined time schedules. Third, even though we did not test for this directly, it is possible that most of the participants were in good mental health, whereas research has shown poor sleep to be associated with increased symptoms of depression, anxiety, and, for instance, eating disorders (see the seminal work of Benca ${ }^{62}$ ).

Our fourth hypothesis, following Hart et $\mathrm{al}^{36}$ was that there would be a U-shaped association between BMI and subjective sleep duration, and our data did fully confirm this, ie, both a shorter and longer subjective sleep duration was associated with increased BMI. Therefore, the present data are in accordance with those studies reporting that both shortened and prolonged sleep duration are associated with a higher BMI. Importantly, the present pattern of results mirrors recent findings among adolescents and participants transitioning from adolescence into adulthood, as reported by Sivertsen et $\mathrm{al}^{33}$ and Suglia et al. ${ }^{32}$

In previous research, authors considered short sleep and obesity to be comorbid conditions. ${ }^{36,37}$ Again, the present data do not allow a deeper understanding of the lack of association. We also note that the median and mode for BMI values in our study participants were within range for the healthy population, so it is conceivable that the lack of difference in BMI might be attributable to a small number of participants with high and low BMIs.

With regard to the relationship between subjective shortened sleep and BMI, we acknowledge that the present data do not allow a deeper understanding of the underlying mechanisms. First, following Taheri et $\mathrm{al}^{63}$ there is evidence that shorter sleep increases the secretion of ghrelin, an appetite-inducing hormone, and decreases secretion of leptin, a satiety-inducing hormone. Second, people with less sleep have more time to eat during the night. Third, if excessive eating behavior is considered a coping strategy, if obese people are under stress because of their negative self-image, and if they receive more negative social feedback regarding their shape, there is reason to assume that obese people increase their calorie intake as a coping strategy to reduce stress. Lallukka et $\mathrm{al}^{64}$ have also demonstrated a close relationship between poor sleep and overweight. Specifically, they were able to show that weight control predicted more favorable sleep over time. Overall, the underlying mechanism accounting for the relationship between poor sleep and overweight remains somewhat unclear; nonetheless, it seems that endocrine, neuroendocrine, and psychologic coping strategies are contributing concomitantly to this relationship.

As regards the association between subjective and prolonged sleep duration and obesity, again our data do not allow a deeper insight into the underlying mechanisms, although the findings of others suggest that obese people are at increased risk of sleep apnea (eg, Mathew and Castriotta ${ }^{65}$ ); in fact, sleep apnea is known to impair sleep quality dramatically and to prolong sleep duration, and we might assume a similar mechanism in the participants in our study.

\section{Limitations}

Several issues indicate that the present findings should not be overgeneralized. First, and most importantly, a selfadministered questionnaire cannot report actual sleep duration but rather gives an estimate or the subjective opinion of participants in regard to their sleep duration. The same applies to sleep need. Therefore, the current assessed actual sleep duration and sleep need always refers to the subjective sleep duration and subjective sleep need, respectively. Second, we assessed only university students, who are not representative of the population of young adults as a whole. Third, only individuals who were willing and able to participate took part in the study, so sampling bias cannot be excluded. Fourth, no data on psychopathology (eg, affective disorders, eating disorders, substance abuse) were collected, and variations in psychopathology might have biased the pattern of associations. In other words, the lack of associations might have been due to further latent but unassessed psychological (eg, symptoms of depression, stress, anxiety) and physiological (eg, cortisol, brain-derived neurotrophic factor) variables 
Fifth, no data were gathered as regards subjective sleep quality and daytime sleepiness or fatigue. These limitations hold particularly true in that no item canvassed respiratory issues such as obstructive sleep apnea or snoring, which, by definition, impair sleep. Sixth, we observed that the mean reported subjective sleep duration of about 8.5 hours matched the recommended sleep duration for young adults. Accordingly, we might question to what extent the present sample of university students reflects young adults as a whole. In this regard, we also note that some participants completed the survey during the summer break, when a more individual and self-paced wake-sleep pattern is more likely. Last, given the cross-sectional nature of the survey, no conclusion can be drawn as to the direction of influence between sleep duration, gender, BMI, and feeling of being restored. A longitudinal study design, like that reported by Nishiura and Hashimoto ${ }^{66}$ would shed more light on the directions of influence between these variables.

\section{Acknowledgments}

The authors thank Corina Tanner for data collection and data entry. They are also grateful to Nick Emler, University of Surrey, UK, for proofreading the manuscript and to the students in Germany and the German-speaking part of Switzerland who participated in this study and contributed to its success. The study was performed with funding from the University of Basel, Basel, Switzerland.

\section{Disclosure}

The authors report no conflicts of interest in this work.

\section{References}

1. Curcio G, Ferrara M, De Gennaro L. Sleep loss, learning capacity and academic performance. Sleep Med Rev. 2006;10:323-337.

2. Dewald JF, Meijer AM, Oort FJ, Kerkhof GA, Bogels SM. The influence of sleep quality, sleep duration and sleepiness on school performance in children and adolescents: a meta-analytic review. Sleep Med Rev. 2010; 14:179-189.

3. Perkinson-Gloor N, Lemola S, Grob A. Sleep duration, positive attitude toward life, and academic achievement: the role of daytime tiredness, behavioral persistence, and school start times. J Adolesc. 2013;36: 311-318.

4. Schabus M, Hodlmoser K, Gruber G, et al. Sleep spindle-related activity in the human EEG and its relation to general cognitive and learning abilities. Eur J Neurosci. 2006;23:1738-1746.

5. Diekelmann S, Born J. The memory function of sleep. Nat Rev Neurosci. 2010;11:114-126.

6. Talbot LS, McGlinchey EL, Kaplan KA, Dahl RE, Harvey AG. Sleep deprivation in adolescents and adults: changes in affect. Emotion. 2010; 10:831-841.

7. Walker MP, van der Helm E. Overnight therapy? The role of sleep in emotional brain processing. Psychol Bull. 2009;135:731-748.

8. Baglioni C, Spiegelhalder K, Lombardo C, Riemann D. Sleep and emotions: a focus on insomnia. Sleep Med Rev. 2010;14:227-238.
9. Walker MP, Harvey AG. Obligate symbiosis: sleep and affect. Sleep Med Rev. 2010;14:215-217.

10. Vandekerckhove M, Cluydts R. The emotional brain and sleep: an intimate relationship. Sleep Med Rev. 2010;14:219-226.

11. Kalak N, Lemola S, Brand S, Holsboer-Trachsler E, Grob A. Sleep duration and subjective psychological well-being in adolescence: a longitudinal study in Switzerland and Norway. Neuropsychiatr Dis Treat. 2014;10:1199-1207.

12. Brand S, Kirov R. Sleep and its importance in adolescence and in common adolescent somatic and psychiatric conditions. Int J Gen Med. 2011;4:425-442.

13. Colrain IM, Baker FC. Changes in sleep as a function of adolescent development. Neuropsychol Rev. 2011;21:5-21.

14. Jan JE, Reiter RJ, Bax MC, Ribary U, Freeman RD, Wasdell MB. Long-term sleep disturbances in children: a cause of neuronal loss. Eur J Paediatr Neurol. 2010;14:380-390.

15. Maret S, Faraguna U, Nelson AB, Cirelli C, Tononi G. Sleep and waking modulate spine turnover in the adolescent mouse cortex. Nat Neurosci. 2011;14:1418-1420.

16. Taylor DJ, Gardner CE, Bramoweth AD, et al. Insomnia and mental health in college students. Behav Sleep Med. 2011;9:107-116.

17. Chatburn A, Coussens S, Kohler MJ. Resiliency as a mediator of the impact of sleep on child and adolescent behavior. Nat Sci Sleep. 2013; 6:1-9.

18. Ohayon MM, Carskadon MA, Guilleminault C, Vitiello MV. Metaanalysis of quantitative sleep parameters from childhood to old age in healthy individuals: developing normative sleep values across the human lifespan. Sleep. 2004;27:1255-1273.

19. Bonnet MH, Arand DL. We are chronically sleep deprived. Sleep. 1995; 18:908-911.

20. Rajaratnam SM, Arendt J. Health in a 24-h society. Lancet. 2001; 358:999-1005.

21. Iglowstein I, Jenni OG, Molinari L, Largo RH. Sleep duration from infancy to adolescence: reference values and generational trends. Pediatrics. 2003;111:302-307.

22. Lemola S, Schwarz B, Siffert A. Interparental conflict and early adolescents' aggression: is irregular sleep a vulnerability factor? J Adolesc. 2012;35:97-105.

23. Mercer PW, Merritt SL, Cowell JM. Differences in reported sleep need among adolescents. J Adolesc Health. 1998;23:259-263.

24. Moore M, Meltzer LJ. The sleepy adolescent: causes and consequences of sleepiness in teens. Paediatr Respir Rev. 2008;9:114-120.

25. Lund HG, Reider BD, Whiting AB, Prichard JR. Sleep patterns and predictors of disturbed sleep in a large population of college students. J Adolesc Health. 2010;46:124-132.

26. Gerber M, Brand S, Holsboer-Trachsler E, Pühse U. Fitness and exercise as correlates of sleep complaints: is it all in our minds? Med Sci Sports Exerc. 2010;42:893-901.

27. Brand S, Gerber M, Beck J, Hatzinger M, Pühse U, Holsboer-Trachsler E. High exercise levels are related to favorable sleep patterns and psychological functioning in adolescents: a comparison of athletes and controls. $J$ Adolesc Health. 2010;46:133-141.

28. McCracken M, Jiles R, Blanck HM. Health behaviors of the young adult U.S. population: behavioral risk factor surveillance system, 2003. Prev Chronic Dis. 2007;4:A25.

29. Lewis CE, Jacobs DR Jr, McCreath H, et al. Weight gain continues in the 1990s: 10-year trends in weight and overweight from the CARDIA study. Coronary Artery Risk Development in Young Adults. Am J Epidemiol. 2000;151:1172-1181.

30. Singh AS, Mulder C, Twisk JW, van Mechelen W, Chinapaw MJ. Tracking of childhood overweight into adulthood: a systematic review of the literature. Obes Rev. 2008;9:474-488.

31. Arnett JJ. Emerging adulthood. A theory of development from the late teens through the twenties. Am Psychol. 2000;55:469-480.

32. Suglia SF, Kara S, Robinson WR. Sleep duration and obesity among adolescents transitioning to adulthood: do results differ by sex? J Pediatr. 2014;165:750-754. 
33. Sivertsen B, Pallesen S, Sand L, Hysing M. Sleep and body mass index in adolescence: results from a large population-based study of Norwegian adolescents aged 16 to 19 years. BMC Pediatr. 2014;14:204.

34. Hasler G, Buysse DJ, Klaghofer R, et al. The association between short sleep duration and obesity in young adults: a 13-year prospective study. Sleep. 2004;27:661-666.

35. Meyer KA, Wall MM, Larson NI, Laska MN, Neumark-Sztainer D. Sleep duration and BMI in a sample of young adults. Obesity (Silver Spring). 2012;20:1279-1287.

36. Hart CN, Larose JG, Fava JL, James BL, Wing RR. The association between time in bed and obesity risk in young adults. Behav Sleep Med. 2013;11:321-327.

37. Patel SR, Hu FB. Short sleep duration and weight gain: a systematic review. Obesity (Silver Spring). 2008;16:643-653.

38. Van Reen E, Sharkey KM, Roane BM, et al. Sex of college students moderates associations among bedtime, time in bed, and circadian phase angle. J Biol Rhythms. 2013;28:425-431.

39. Zhang B, Wing YK. Sex differences in insomnia: a meta-analysis. Sleep. 2006;29:85-93.

40. Armitage R, Hoffmann RF. Sleep EEG, depression and gender. Sleep Med Rev. 2001;5:237-246.

41. Hyde JS, Mezulis AH, Abramson LY. The ABCs of depression: integrating affective, biological, and cognitive models to explain the emergence of the gender difference in depression. Psychol Rev. 2008;115:291-313.

42. Maslowsky J, Ozer EJ. Developmental trends in sleep duration in adolescence and young adulthood: evidence from a national United States sample. J Adolesc Health. 2014;54:691-697.

43. Buboltz WC Jr, Brown F, Soper B. Sleep habits and patterns of college students: a preliminary study. J Am Coll Health. 2001;50:131-135.

44. Van Dongen HP, Maislin G, Mullington JM, Dinges DF. The cumulative cost of additional wakefulness: dose-response effects on neurobehavioral functions and sleep physiology from chronic sleep restriction and total sleep deprivation. Sleep. 2003;26:117-126.

45. Vandekerckhove M, Kestemont J, Weiss R, et al. Experiential versus analytical emotion regulation and sleep: breaking the link between negative events and sleep disturbance. Emotion. 2012;12:1415-1421.

46. Killgore WD, Kahn-Greene ET, Lipizzi EL, Newman RA, Kamimori GH, Balkin TJ. Sleep deprivation reduces perceived emotional intelligence and constructive thinking skills. Sleep Med. 2008;9:517-526.

47. Lemola S, Ledermann T, Friedman EM. Variability of sleep duration is related to subjective sleep quality and subjective well-being: an actigraphy study. PLoS One. 2013;8:e71292.

48. Vargas PA, Flores M, Robles E. Sleep quality and body mass index in college students: the role of sleep disturbances. J Am Coll Health. 2014;62:534-541.

49. Magee L, Hale L. Longitudinal associations between sleep duration and subsequent weight gain: a systematic review. Sleep Med Rev. 2012;16:231-241.
50. Carskadon MA, Acebo C. Regulation of sleepiness in adolescents: update, insights, and speculation. Sleep. 2002;25:606-614.

51. Carskadon MA, Acebo C, Jenni OG. Regulation of adolescent sleep: implications for behavior. Ann N Y Acad Sci. 2004;1021: 276-291.

52. Mangunkusumo RT, Moorman PW, Van Den Berg-de Ruiter AE, Van Der Lei J, De Koning HJ, Raat H. Internet-administered adolescent health questionnaires compared with a paper version in a randomized study. J Adolesc Health. 2005;36:70.e71-e76.

53. Vereecken CA, Maes L. Comparison of a computer-administered and paper-and-pencil-administered questionnaire on health and lifestyle behaviors. J Adolesc Health. 2006;38:426-432.

54. Wang YC, Lee CM, Lew-Ting CY, Hsiao CK, Chen DR, Chen WJ. Survey of substance use among high school students in Taipei: webbased questionnaire versus paper-and-pencil questionnaire. J Adolesc Health. 2005;37:289-295.

55. Welch BL. The generalization of students problem when several different population variances are involved. Biometrika. 1947;34: 28-35.

56. Scheffé H. Practical solutions to the Behrens-Fisher problem. J Am Stat Assoc. 1970;65:1501-1508.

57. Kaneita Y, Ohida T, Osaki Y, et al. Association between mental health status and sleep status among adolescents in Japan: a nationwide crosssectional survey. J Clin Psychiatry. 2007;68:1426-1435.

58. Cohen J. Statistical power analysis for the behavioral sciences. Percept Mot Skills. 1988;67:1007.

59. Zhu WM. Sadly, the earth is still round $(P<0.05)$. J Sport Health Sci. 2012;1:9-11.

60. Matsushita M, Koyama A, Ushijima H, et al. Sleep duration and its association with sleepiness and depression in "ronin-sei" preparatory school students. Asian J Psychiatr. 2014;9:61-66.

61. Lau EY, Wong ML, Ng EC, Hui CC, Cheung SF, Mok DS. "Social jetlag" in morning-type college students living on campus: implications for physical and psychological well-being. Chronobiol Int. 2013;30: 910-918.

62. Benca RM. Sleep in psychiatric disorders. Neurol Clin. 1996;14: 739-764.

63. Taheri S, Lin L, Austin D, Young T, Mignot E. Short sleep duration is associated with reduced leptin, elevated ghrelin, and increased body mass index. PLoS Med. 2004;1:e62.

64. Lallukka T, Haario P, Lahelma E, Rahkonen O. Associations of relative weight with subsequent changes over time in insomnia symptoms: a follow-up study among middle-aged women and men. Sleep Med. 2012;13:1271-1279.

65. Mathew R, Castriotta RJ. High hypopnea/apnea ratio (HAR) in extreme obesity. J Clin Sleep Med. 2014;10:391-396.

66. Nishiura C, Hashimoto H. Sleep duration and weight gain: reconsideration by panel data analysis. J Epidemiol. 2014;24(5):404-409.
Neuropsychiatric Disease and Treatment

\section{Publish your work in this journal}

Neuropsychiatric Disease and Treatment is an international, peerreviewed journal of clinical therapeutics and pharmacology focusing on concise rapid reporting of clinical or pre-clinical studies on a range of neuropsychiatric and neurological disorders. This journa is indexed on PubMed Central, the 'PsycINFO' database and CAS,

\section{Dovepress}

and is the official journal of The International Neuropsychiatric Association (INA). The manuscript management system is completely online and includes a very quick and fair peer-review system, which is all easy to use. Visit http://www.dovepress.com/testimonials.php to read real quotes from published authors. 